\title{
Characteristics of Antinociception Induced by Noncatecholic Phenylethylamine Derivatives: The Relation of Endogenous Norepinephrine to Phenylethylamine Analog-Induced Antinociception
}

\author{
Yutaka MATSUOKA, Masafumi SAKUMA, Toshihiko SUGIOKA, \\ Yasufumi TERAWAKI, Tsutomu URUNO and Kazuhiko KUBOTA \\ Department of Pharmacology. Faculty of Pharmaceutical Sciences, \\ Science University of Tokyo, 12 Ichigaya-Funagawara-machi, \\ Shinjuku-ku, Tokyo 162, Japan \\ Accepted June 30, 1988
}

\begin{abstract}
Characteristics of the antinociceptive action of phenylethylamine derivatives, amphetamine, $\beta$-phenylethylamine (PEA) and $\beta$-hydroxyphenylethylamine (OHPEA), were examined. The pain threshold of mice was measured by using the hot plate method. Intraperitoneal administration of $\alpha$-methyl-p-tyrosine inhibited antinociception induced by PEA and OHPEA, and intracisternal administration of norepinephrine increased antinociception induced by PEA and OHPEA. Intracisternal administration of phentolamine inhibited the antinociception induced by PEA derivatives. The levels of norepinephrine and normetanephrine in the brain were determined by using HPLC. PEA derivatives decreased norepinephrine in the brain and tended to increase normetanephrine at $15 \mathrm{~min}$ after the administration of PEA derivatives. These findings indicate that PEA derivatives cause the release of norepinephrine in the central nervous system, and the released norepinephrine induces antinociception.
\end{abstract}

The existence of $\beta$-phenylethylamine (PEA) has been demonstrated in the brain and body fluids of various species of animals including humans (1), and it has been postulated that PEA may function as a neuromodulator in the central nervous system (CNS) (2). Giardina (3) reported that PEA and $\beta$-hydroxyphenylethylamine (OHPEA) induce an antinociceptive effect in pargylinepretreated mice. Amphetamine, one of the noncatecholic phenylethylamine derivatives, has been well-known to produce a slight but significant antinociceptive action (4). We (5) have also reported that $P E A$ derivatives such as PEA, OHPEA and amphetamine have antinociceptive actions, and the actions involve the participation of endogenous serotonin and endogenous opioid peptides.

Braestrup and Randrup (6) reported that PEA appears to have a strong action of releasing norepinephrine in the central nervous system (CNS). Takagi and his colleagues $(7,8)$ reported that the antinociception induced by morphine injected into the nucleus reticularis gigantocellularis (NRGC) or the nucleus reticularis paragigantocelluraris (NRPG) and by electrostimulation applied to the NRGC or NRPG was inhibited by phenoxybenzamine, an adrenergic $\alpha$ blocker. Furthermore, clonidine, one of the adrenergic $\alpha_{2}$-agonists, has been reported to induce antinociception related to the lower brain stem structure (9). These findings suggest that norepinephrine in the CNS may play an important role in the antinociceptive pathways.

The aim of the present study was to clarify the correlation of endogenous norepinephrine to the antinociception induced by PEA derivatives, through examining the effects of agonists and antagonists to adrenergic receptors on PEA analog-induced 
antinociception and the effects of PEA derivatives on norepinephrine contents in the brain of mice.

\section{Materials and Methods}

Materials: Amphetamine sulfate (Zedrin, Takeda Chem. Ind., Osaka), DL- $\beta$-hydroxyphenylethylamine (OHPEA; Sigma, St. Louis, MO, U.S.A.) and $\beta$-phenylethylamine hydrochloride (PEA; Tokyo Kasei, Tokyo) were used as PEA derivatives. L-Norepinephrine bitartrate (Sigma), phenylephrine hydrochloride (Sigma), phentolamine mesylate (Ciba-Geigy, Switzerland), $\quad \alpha$-methyl-ptyrosine ( $\alpha$-MPT: Sigma) and pargyline hydrochloride (Nakarai Chem., Kyoto) were used for pretreatment drugs in the hot plate method.

L-Norepinephrine bitartrate and normetanephrine hydrochloride (NM: Sigma) were used for the standard substances in the HPLC method.

Measurement of antinociceptive effect: Male ddY mice (Shizuoka Laboratory Animal Center, Hamamatsu), weighing 17 to $20 \mathrm{~g}$. were used. Pain thresholds of mice were measured by using the hot plate method of Woolf and MacDonald (10). The hot plate was maintained at $55 \pm 0.5^{\circ} \mathrm{C}$ by using a thermistor. In order to determine pain thresholds of mice, the latency, the length of time which mice placed on the hot plate required to initiate any one of the following behaviors, jumping or shaking, licking. holding or lifting their paws, was measured in a room kept at $24 \pm 1{ }^{\circ} \mathrm{C}$ and at $55 \pm 5 \%$ relative humidity and protected from external noise. Mice were preliminarily tested twice for the latency, and those showing a latency ranging from 3 to $10 \mathrm{sec}$ were used for the experiments. The pain thresholds of mice were measured at $15 \mathrm{~min}$ and immediatery before and at $15,30,45,60,90$ and $120 \mathrm{~min}$ after the i.p. administration of PEA derivatives.

In the case of observing the effect of peripherally administered drugs on PEA analog-induced antinociception, the drugs except $\alpha$-MPT were dissolved in saline. $\alpha$ MPT was suspended in saline with a few drops of Tween 40 (Kanto Chemical Co., Tokyo). These drugs were i.p. injected to mice $15 \mathrm{~min}$ before the administration of PEA derivatives, except for the administration of $\alpha$-MPT and pargyline. $\alpha$-MPT and pargyline were i.p. injected $24 \mathrm{hr}$ and $16 \mathrm{hr}$ before PEA derivatives, respectively.

In the case of observing the effect of centrally administered norepinephrine and phentolamine, $10 \mu \mathrm{l}$ of an aqueous solution $(0.5 \mu \mathrm{g} / \mu l)$ of norepinephrine was injected into the cerebro-medullary cistern of a mouse by the the method of Ueda et al. (11) $5 \mathrm{~min}$ after the i.p. administration of PEA derivatives, and phentolamine $(4 \mu \mathrm{g} / 10 \mu$ of pure water) was intracisternally administered $15 \mathrm{~min}$ before the PEA derivatives. For the control, $10 \mu l$ of water was intracisternally injected at the corresponding time.

Quantitative determination of norepinephrine and normetanephrine in the mouse brain: Male ddY mice, weighing 25 to $30 \mathrm{~g}$, were used. Experiments were conducted in a period from $12: 00$ to $15: 00$ in order to minimize the effects of circadian rhythm on biogenic amines and their metabolism in mice. At $15 \mathrm{~min}$ or at $60 \mathrm{~min}$ after the i.p. injection of $2 \mathrm{mg} / \mathrm{kg}$ of AM, $50 \mathrm{mg} / \mathrm{kg}$ of PEA or 50 $\mathrm{mg} / \mathrm{kg}$ of OHPEA, mice were directly dropped into liquid nitrogen, and then the whole brain including the cerebellum and the medulla oblongata was quickly removed, weighed and homogenized in 10 volumes by weight of 0.1 $\mathrm{N}$ perchloric acid aqueous solution containing $0.2 \% \mathrm{~L}$-ascorbic acid and $0.2 \%$ disodium ethylene-diamine-tetraacetic acid ( $\mathrm{Na}_{2}$ EDTA) by using a glass homogenizer at $4^{\circ} \mathrm{C}$. Following a centrifugation of the homogenate at $10,000 \times \mathrm{g}$ for $20 \mathrm{~min}$, at $4^{\circ} \mathrm{C}$, the supernatant obtained was adjusted to $\mathrm{pH} 7.5-8.5$ with $1.0 \mathrm{M} \mathrm{K}_{2} \mathrm{HPO}_{4}$ and recentrifuged at $10,000 \times \mathrm{g}$ for $15 \mathrm{~min}$, at $4^{\circ} \mathrm{C}$. According to the method of Karasawa et al. (12), the supernatant was applied to a column, $3.0 \mathrm{~cm}$ long and $0.4 \mathrm{~cm}$ in diameter, with a $8 \mathrm{ml}$ reservoir filled with Amberlite CG-50, which had been equilibrated with $0.1 \mathrm{M}$ sodium phosphate buffer ( $\mathrm{pH}$ 6.0). After washing the column with $7 \mathrm{ml}$ of water, norepinephrine and the metabolite were eluted using $3.0 \mathrm{ml}$ of $1.0 \mathrm{~N} \mathrm{HCl}$. After the Iyophilization of the eluate, the residue was added with $200 \mu$ of the mobile phase described below. A $20 \mu l$ aliquot was subjected to HPLC. Amberlite CG-50 (Type II $\mathrm{H}^{+}$form, 100-200 mesh, Rohm \& Haas, 
Philadelphia, U.S.A.) had been previously converted to the $\mathrm{Na}^{+}$form by the method of Ogasawara et al. (13).

A dual pump HPLC system (NPG-500E, $51 \mathrm{~K} 40$ PGK-A 2 : Nihon Seimitsu Kagaku Co., Tokyo) equipped with a $25 \mathrm{~cm} \times 4.5 \mathrm{~mm}$ i.d. stainless steel column filled with Hitachi-Gel ODS $5 \mu \mathrm{m}$ was used for separation of norepinephrine and normetanephrine (NM). The mobile phase was of the following composition: $0.1 \mathrm{M} \mathrm{KH}_{2} \mathrm{PO}_{4}, 130 \mu \mathrm{M} \mathrm{Na} \mathrm{N}_{2}$ EDTA, $8 \mathrm{mM}$ hexane sulfonate sodium (ion-pairing reagent) and $4.76 \%$ (vol./vol.) ethanol; it's $\mathrm{pH}$ was adjusted to 2.85 by $0.1 \mathrm{M} \mathrm{H}_{3} \mathrm{PO}_{4}$ and then degassed by an ultrasonic cleaner (Tokyo Rika Kikai, Tokyo). The flow rate was fixed at $0.8 \mathrm{ml} / \mathrm{min}$. Fluorescence of the amines was detected at $280 \mathrm{~nm}$ for excitation and at $340 \mathrm{~nm}$ for emission (slit width of 10 $\mathrm{nm}$, respectively) with a Shimadzu spectrofluorophotometer RF540 (Shimadzu, Kyoto) equipped with an LC flow cell unit with a $120 \mu$ cell (Shimadzu, Kyoto). A standard mixture containing $500 \mathrm{ng} / \mathrm{ml}$ each of norepinephrine and NM was analyzed at the start of the HPLC analysis, after the analysis of every six samples, and at the end of a series of analyses, in order to confirm that the peak heights of the standard mixture were kept constant during the analysis. The recoveries of the amines throughout the whole procedure were about $80 \%$ for norepinephrine and almost $100 \%$ for NM.

Statistics: Results were expressed as the mean \pm S.E. Statistical significance was assessed by Student's $t$-test with two-tailed probability for unpaired data. A difference was considered significant at the $P<0.05$ level.

\section{Results}

Effects of peripheral administration of several adrenergic-agonists and antagonists on PEA analog-induced antinociception: Intraperitoneal administration of 2 or $4 \mathrm{mg}$ / $\mathrm{kg}$ of amphetamine, $50 \mathrm{mg} / \mathrm{kg}$ of PEA or $50 \mathrm{mg} / \mathrm{kg}$ of OHPEA induced a significant increment of the latency in the hot plate method (Figs. 1, 2, 4, 5).

An i.p. administration of $5 \mathrm{mg} / \mathrm{kg}$ of phenylephrine, which had no effect on the latency in mice, tended to decrease the antinociception induced by $4 \mathrm{mg} / \mathrm{kg}$ of amphetamine and $50 \mathrm{mg} / \mathrm{kg}$ of OHPEA $(P<0.05)$, and it did not affect the PEA (50 $\mathrm{mg} / \mathrm{kg}$ )-induced antinociception (Fig. 1). On the other hand, an i.p. administration of $5 \mathrm{mg} / \mathrm{kg}$ of phentolamine did not induce antinociception per se, and it had no effect on antinociception induced by $4 \mathrm{mg} / \mathrm{kg}$ of amphetamine, $50 \mathrm{mg} / \mathrm{kg}$ of PEA and $50 \mathrm{mg} /$ $\mathrm{kg}$ of OHPEA (the data are not shown).

Pretreatment with $100 \mathrm{mg} / \mathrm{kg}$, i.p., of $\alpha$ MPT, a norepinephrine-depleting drug, which had little influence on the latency, inhibited the antinociception induced by PEA or by OHPEA with statistical significance $(P<0.05$ and $P<0.01$, respectively), but failed to weaken the antinociception induced by $4 \mathrm{mg} /$ $\mathrm{kg}$ of amphetamine (Fig. 2).

$\alpha$-MPT induced slight increment of the latency after several measurements of the threshold. Concomitant administration of $\alpha$ MPT and pargyline induced a prolonged antinociception (Fig. 3).

Effect of central administration of norepinephrine and phentolamine on PEA analog-induced antinociception: Intracisternal administration of norepinephrine had little influence on the latency in the hot plate method, and it enhanced the antinociception induced by PEA and that by OHPEA $(P<0.01$ and $P<0.05$, respectively), but did not affect the amphetamine $(2 \mathrm{mg} / \mathrm{kg})$-induced antinociception (Fig. 4). On the other hand, phentolamine (4 $\mu \mathrm{g} /$ mouse) did not affect the latency by itself, and it inhibited the antinciception induced by amphetamine, PEA and OHPEA (Fig. 5).

Effect of PEA derivatives on the contents of monoamines and their metabolites in the mouse whole brain: A typical HPLC chromatographic pattern of the separation of norepinephrine and NM are shown in Fig. 6 . The contents of norepinephrine and NM in the whole brain from the control mice treated with saline at $15 \mathrm{~min}$ before the sacrifice were $305.9 \pm 10.1 \mathrm{ng} / \mathrm{g}$ and $23.4 \pm 3.3 \mathrm{ng} / \mathrm{g}$ wet tissue weight (mean \pm S.E., 6 mice), respectively, and their contents in the control mice treated with saline at $60 \mathrm{~min}$ before the sacrifice were $309.3 \pm 6.5 \mathrm{ng} / \mathrm{g}$ and $26.2 \pm 3.7$ $\mathrm{ng} / \mathrm{g}$ wet tissue weight (6 mice), respectively. Norepinephrine contents were significantly 
decreased by PEA derivatives at $15 \mathrm{~min}$ phetamine, $50 \mathrm{mg} / \mathrm{kg}$ of $P E A$ or $50 \mathrm{mg} / \mathrm{kg}$ after the administration of $2 \mathrm{mg} / \mathrm{kg}$ of am- of OHPEA $(P<0.05, P<0.01$ and $\mathrm{P}<0.05$,
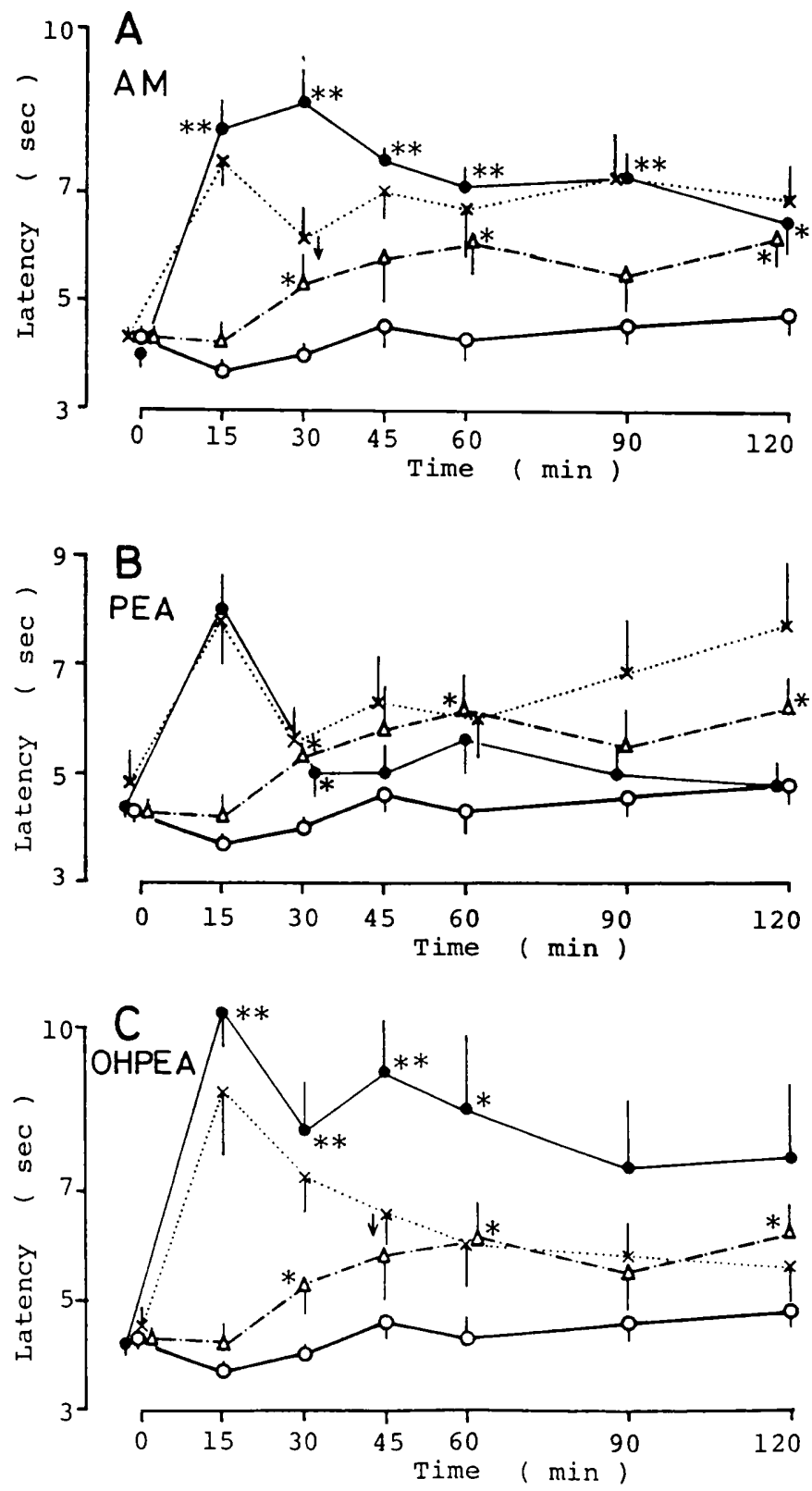

Fig. 1. Effects of i.p. administration of phenylephrine on antinociception induced by amphetamine (A), PEA (B) and OHPEA (C). Phenylephrine $(5 \mathrm{mg} / \mathrm{kg}$ ) was injected at $15 \mathrm{~min}$ before treatment with $4 \mathrm{mg} /$ $\mathrm{kg}$ of amphetamine, $50 \mathrm{mg} / \mathrm{kg}$ of PEA or $50 \mathrm{mg} / \mathrm{kg}$ of OHPEA. Each point represents the mean value of the latency of 8 mice in the hot plate method. Vertical bars show the S.E. Symbols represent $O$ : control; -: amphetamine (A). PEA (B) or OHPEA (C): $\triangle$ : phenylephrine; $x$ : phenylephrine+PEA derivatives. Significant difference from the control by Student's $t$-test: ${ }^{* *} P<0.01,{ }^{*} P<0.05$, and significant difference from the values of PEA analog-treated mice: $\downarrow P<0.05$. 

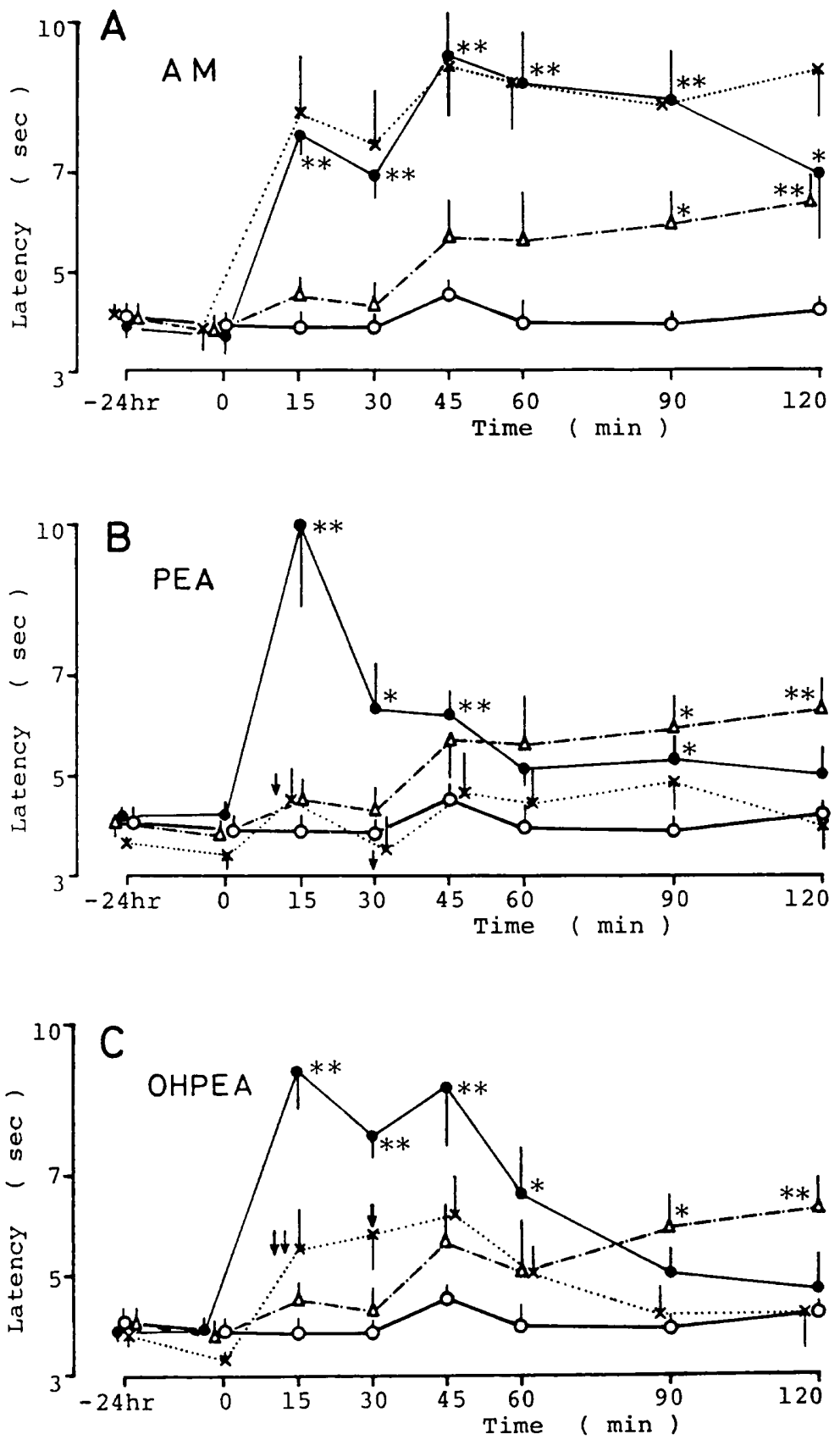

Fig. 2. Effects of i.p. injection of $\alpha$-methyl-p-tyrosine ( $\alpha$-MPT) on antinociception induced by amphetamine (A), PEA (B) or OHPEA (C). $\alpha$-MPT was treated $24 \mathrm{hr}$ before PEA analog treatment. Each point represents the mean value. Vertical bars show the S.E. Symbols represent $\bigcirc$ : control (8); amphetamine (6) in (A). PEA (10) in (B) and OHPEA (10) in (C): $\triangle: \alpha$-MPT (8): $\times: \alpha-M P T+P E A$ derivatives (8), where figures in parentheses indicate the number of mice. Significant difference from the control by Student's $t$-test: ${ }^{*} P<0.01,{ }^{*} P<0.05$; and significant difference from $P E A$ derivatives: $\downarrow \downarrow P<0.01, \downarrow P<0.05$. 


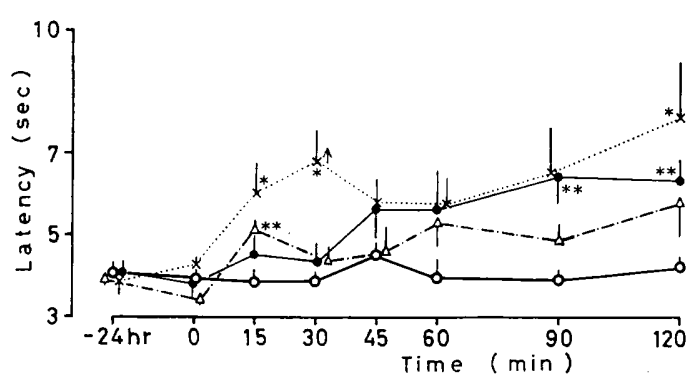

Fig. 3. Effects of $\alpha$-methyl-p-tyrosine ( $\alpha$-MPT) and/or pargyline on the latency in the mouse hot plate method. Pargyline $(100 \mathrm{mg} / \mathrm{kg})$ and $\alpha$-MPT were i.p. injected $16 \mathrm{hr}$ and $24 \mathrm{hr}$ before the start of the latency measurement, respectively. Each point represents the mear, value of 8 mice. Vertical bars show the S.E. Symbols represent $O$ : control; $\alpha$-MPT: $\triangle$ : pargyline: $\times: \alpha$-MPT+pargyline. Significant difference from the control by Student's $t$ test: ${ }^{* *} \mathrm{P}<0.01$, ${ }^{*} \mathrm{P}<0.05$, and significant difference from the value of $\alpha$-MPT-treated mice: $\uparrow \mathrm{P}<0.05$.

respectively), and they returned to the normal level $60 \mathrm{~min}$ after the administration of PEA derivatives (Fig. 7). On the contrary, NM contents in the whole brain were significantly increased 15 min after the administration of amphetamine, PEA or OHPEA $(P<0.05$, $P<0.01$ and $P<0.05$, respectively), and they also returned to the normal level $60 \mathrm{~min}$ after the administration of PEA derivatives.

\section{Discussion}

The results obtained in the present work are summarized in Table 1. Intraperitoneal injection of amphetamine, PEA or OHPEA significantly increased the latency of mice in the hot plate method (Figs. 1, 2, 4, 5), suggesting that the PEA derivatives possess antinociceptive activities.

Tocco et al. (14) reported that i.p. injection of $\alpha$-antagonists, such as phentolamine or yohimbine, did not affect amphetamineinduced antinociception in mice in the hot plate method. Kihara and Kaneto (15) reported that i.p. injection of phentolamine revealed no analgesic effects and did not influence morphine analgesia in the modified Haffner's method of using mice. The present work demonstrated that i.p. treatment with $5 \mathrm{mg} / \mathrm{kg}$ of phentolamine could not affect the antinociception induced by PEA derivatives.
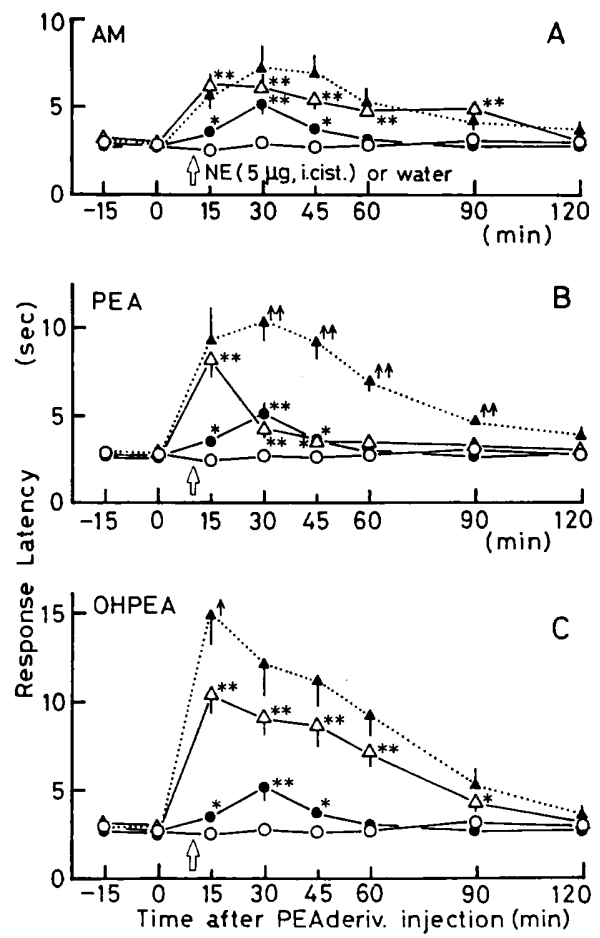

Fig. 4. Effects of intracisternal administration of norepinephrine on antinociception induced by amphetamine (A), PEA (B) or OHPEA (C). The time of intracisternal irijection of norepinephrine $(5 \mu \mathrm{g} /$ mouse) was at $5 \mathrm{~min}$ after the i.p. injection with 2 $\mathrm{mg} / \mathrm{kg}$ of amphetamine, $50 \mathrm{mg} / \mathrm{kg}$ of PEA or $50 \mathrm{mg} /$ $\mathrm{kg}$ of OHPEA, being indicated by white arrows (仓). Each point represents the mean value of latency from 10 mice. Vertical bars show the S.E. Symbols represent $O$ : control (saline+water): $O$ : norepinephrine: $\triangle$ : PEA derivatives; $\mathbf{\Delta}$ : norepinephrine+PEA derivatives. Significant difference from the control by Student's t-test: ${ }^{* *} P<0.01,{ }^{*} P<0.05$; and significant difference from PEA derivatives: $\uparrow \uparrow P<0.01$, $\uparrow P<0.05$.

PEA is known to pass through the bloodbrain barrier with ease (16), and it rapidly accumulates in the brain (17). Therefore, PEA derivatives may act in the brain. Their antinociceptive effects were unaffected by a peripheral administration of an $\alpha$-antagonist such as phentolamine in the present study. Furthermore, in contrast to the effects of the intracisternal administration of an $\alpha$-agonist, norepinephrine (Fig. 4), i.p. administration of $5 \mathrm{mg} / \mathrm{kg}$ of phenylephrine, which is an $\alpha-$ agonist, tended to decrease antinociception 

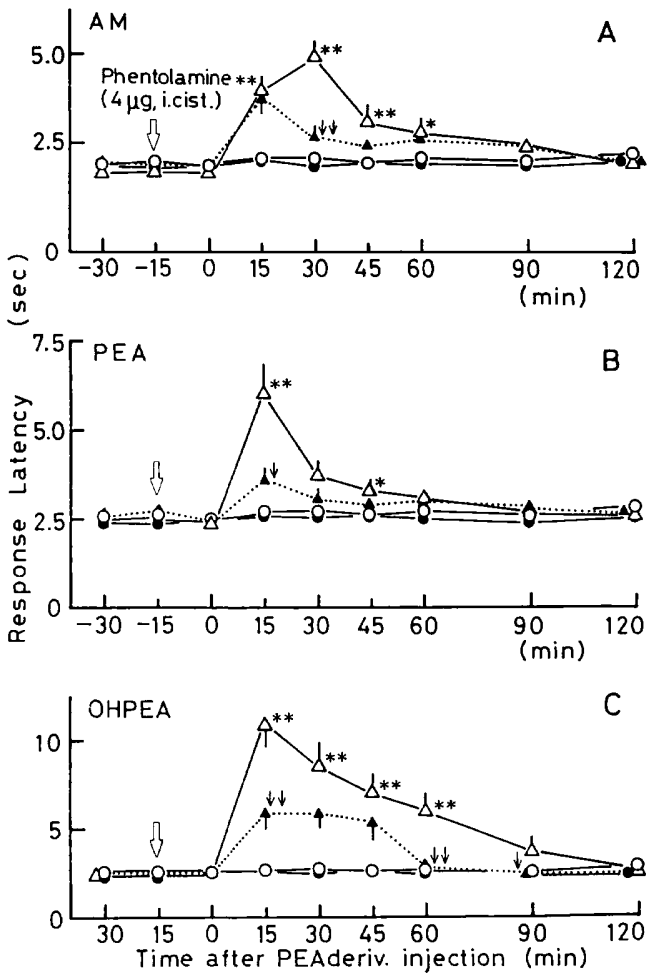

Fig. 5. Effects of intracisternal administration of phentolamine on antinociception induced by amphetamine (A), PEA (B) or OHPEA (C). The time of intracisternal injection with phentolamine $(4 \mu \mathrm{g} /$ mouse) was at $15 \mathrm{~min}$ before the i.p. injection of 2 $\mathrm{mg} / \mathrm{kg}$ of amphetamine, $50 \mathrm{mg} / \mathrm{kg}$ or $50 \mathrm{mg} / \mathrm{kg}$ of OHPEA, being indicated by white arrows $(\zeta)$ in the figure. Each point represents the mean value of latency from 10 mice. Vertical bars show the S.E. Symbols represent $\bigcirc$ : control; $\bigcirc$ : phentolamine; $\triangle$ : PEA derivatives: $\boldsymbol{\Delta}$ : phentolamine + PEA derivatives. Significant difference from the control by Student's $t$-test: ${ }^{* *} P<0.01,{ }^{*} P<0.05$; and significarit difference from PEA derivatives: $\downarrow \downarrow P<0.01, \downarrow P<0.05$.

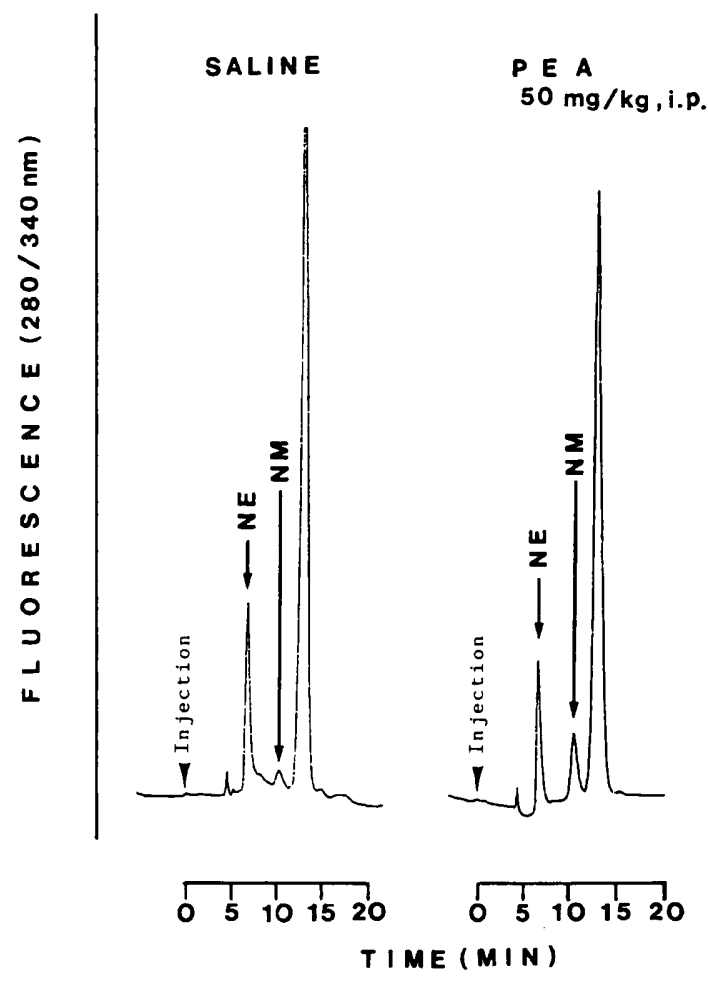

Fig. 6. The typical pattern of HPLC separation of norepinephrine (NE) and normetanephrine (NM) extracted from the whole brains of a control mouse and one that recieved $50 \mathrm{mg} / \mathrm{kg}$ of PEA. These traces were made by the detection of fluorescence at 280 $\mathrm{nm}$ for excitation and at $340 \mathrm{~nm}$ for emission, and they were obtained from the control mouse (left trace) and PEA-treated mouse (right trace) at $15 \mathrm{~min}$ after the treatment.

Table 1. Characteristics of antinociception induced by phenylethylamine derivatives

\begin{tabular}{|c|c|c|c|c|c|}
\hline & \multirow[b]{3}{*}{$\begin{array}{l}\text { Dose } \\
\mathrm{mg} / \mathrm{kg}\end{array}$} & \multirow[b]{3}{*}{ Alone } & \multicolumn{3}{|c|}{ Pretreatment with } \\
\hline & & & \multirow{2}{*}{$\frac{\text { i.p. inj. of }}{\alpha-\mathrm{MPT}}$} & \multicolumn{2}{|c|}{ i.cist. inj. of } \\
\hline & & & & $\begin{array}{c}\mathrm{NE} \\
5 \mu \mathrm{g} / \mathrm{mouse}\end{array}$ & $\begin{array}{c}\text { Phent } \\
4 \mu \mathrm{g} / \text { mouse }\end{array}$ \\
\hline OHPEA & 50 & + & $\downarrow$ & $\bar{\uparrow}$ & $\downarrow$ \\
\hline PEA & 50 & + & $\downarrow$ & $\uparrow$ & $\downarrow$ \\
\hline \multirow[t]{2}{*}{$A M$} & 4 & + & \pm & & \\
\hline & 2 & + & & \pm & $\downarrow$ \\
\hline
\end{tabular}

Abbreviations: OHPEA: $\beta$-hydroxyphenylethylamine, PEA: $\beta$-phenylethylamine, AM: amphetamine, $\alpha$-MPT: $\alpha$-methyl-p-tyrosine, NE: norepinephrine, Phent: phentolamine, i.cist.: intracisternally. $\downarrow$ : decrease of antinociception, $\uparrow:$ increase of antinociception, \pm : no effect on antinociception, $+:$ produces antinociception. 


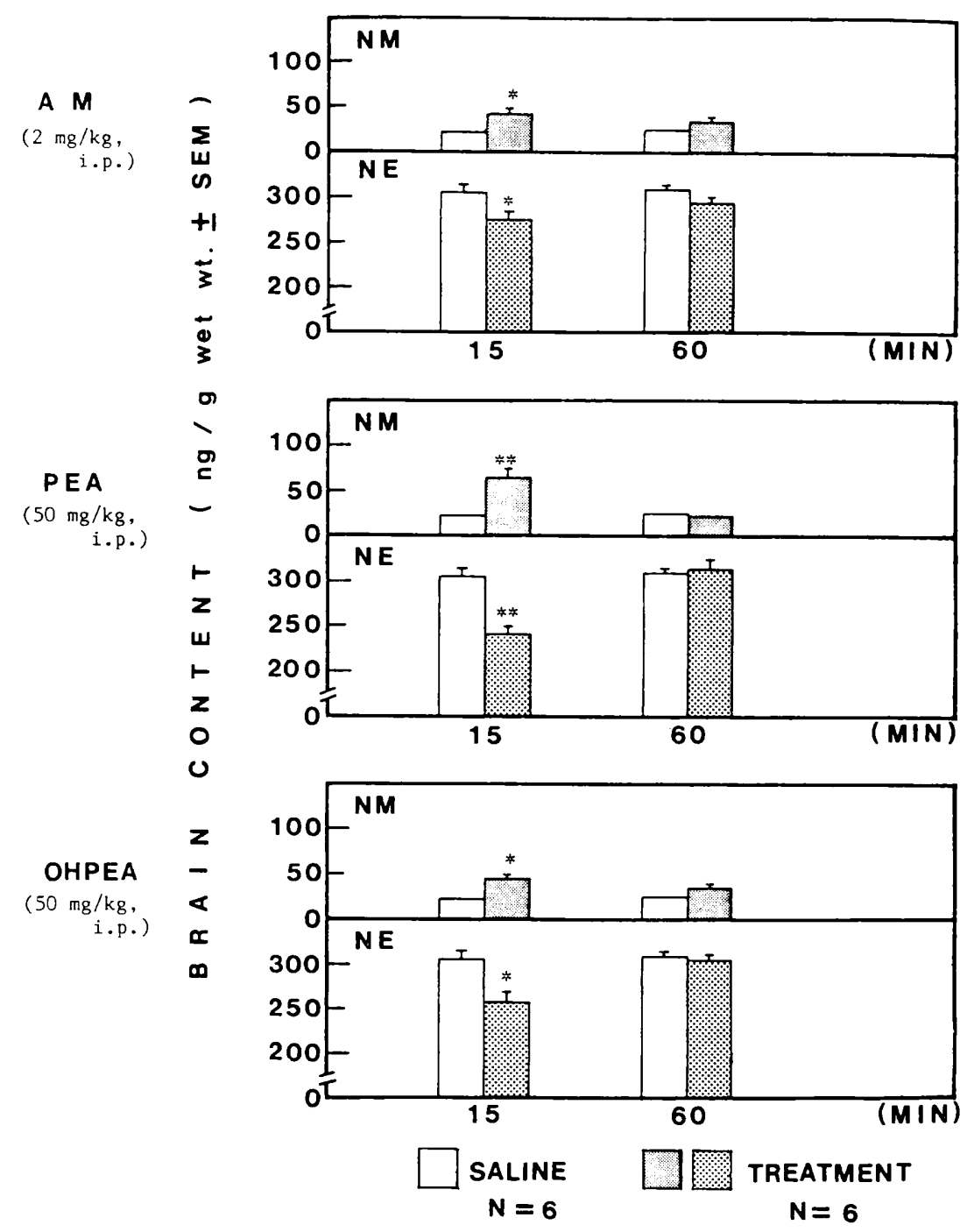

Fig. 7. Normetanephrine (NM) and norepinephrine (NE) levels (ng/g tissue wet weight) in the whole brain of mice treated with or without PEA derivatives at $15 \mathrm{~min}$ and at $60 \mathrm{~min}$ before the sacrifice. Open columns indicate the levels in control mice and closed ones the levels in mice treated with PEA derivatives. Each column represents the mean value of 6 mice. Vertical bars show the S.E. Statistically significant difference from saline treated mice by Student's $t$-test: ${ }^{*} P<0.05,{ }^{* *} P<0.01$.

induced by PEA derivatives (Fig. 1). It is wellknown that $\alpha$-adrenergic agonists and antagonists produce effects through acting on peripheral organs such as blood vessels and the heart. Therefore, care must be taken for the interpretation of the results from peripheral administration of $\alpha$-adrenergic agonists and antagonists. Then, in order to minimize peripheral actions by $\alpha$-agonists and $\alpha$-antagonists, norepinephrine and phentolamine were administered intracisternally for observing their effect on PEA analoginduced antinociception.

Intracisternal injection of $5 \mu \mathrm{g} /$ mouse of norepinephrine potentiated antinociception by PEA or OHPEA, and it did not affect that by amphetamine (Fig. 4). Intracisternal injection of $4 \mu \mathrm{g} /$ mouse of phentolamine 
inhibited antinociception by PEA derivatives (Fig. 5). Intraperitoneal pretreatment with 100 $\mathrm{mg} / \mathrm{kg}$ of $\alpha$-MPT, an inhibitor of catecholamine syntheses (18), inhibited antinociception induced by PEA and OHPEA, but failed to inhibit that by amphetamine (Fig. 2). These results suggest that PEA analoginduced antinociception involves endogenous norepinephrine in the CNS, and there is little difference between the characteristics in antinociception induced by PEA or OHPEA and that by amphetamine.

Concomitant administration of $\alpha$-MPT and pargyline induced a slight antinociception after the repeated measurements of latency. This result suggests that $\alpha$-MPT can not completely deplete endogenous norepinephrine in the CNS and a monoamine oxidase (MAO) inhibitor might produce antinociceptive activity under the pretreatment of $\alpha$ MPT. It is well-known that amphetamine inhibits MAO (19). The MAO inhibitory action of amphetamine may concerned with the characteristic of antinociception by amphetamine. Therefore, amphetamine may differ slightly from PEA and OHPEA with respect to the characteristics of antinociception. However, we do not have a more precise explanation at present.

Braestrup and Randrup (6) reported that PEA appears to have strong norepinephrinereleasing action in the CNS. Since catechol$\mathrm{O}$-methyltransferase (COMT) is believed to be located extraneuronally $(20,21)$, normetanephrine (NM), to which norepinephrine is metabolized by COMT, provides a good index for the release of norepinephrine (12). Then, the brain levels of norepinephrine and its metabolite, normetanephrine, were determined by an HPLC method. PEA derivatives decreased the brain level of norepinephrine, and they tended to increase that of NM at 15 min after the injection, and the changed levels returned to the control levels $60 \mathrm{~min}$ after the injection of PEA derivatives (Fig. 7). These results suggest that PEA derivatives may release norepinephrine in the CNS.

It has been demonstrated that antinociceptive action by PEA derivatives may involve endogenous serotonin and endogenous opioid peptides (5). Besides these mechanisms, the above findings in the present study suggests the following: PEA derivatives may induce the release of norepinephrine in the CNS, and then the released norepinephrine may also produce an antinociception.

\section{References}

1 Ho, B.T.: Behavioral effects of phenylethylamineneurochemical correlates. In Noncatecholic Phenylethylamines, Part 1, Edited by Mosnaim. A.D. and Wolf, M.T., p. 271-287, Marcel Dekker, New York and Basel (1978)

2 Sabelli, H.C., Mosnaim, A.D. and Vazquez, A.J.: Phenylethylamine: Possible role in depression and antidepressive drug action. In Advances in Behavioral Biology, Vol. 10, Neurohormonal Coding of Brain Function, Edited by Mayers, R.D. and Drucker-Colin. R.R., p. 331-357, Plenum Press, New York (1974)

3 Giardina, W.J.: Analgesic properties of phenylethylamine and phenylethanolamine in mice. Pharmacology 12, 1-6 (1974)

4 Kameyama, T.: Studies on analgesics. VIAnalgesic activity of sympathomimetic amines and other drugs. Yakugaku Zasshi 81, 215-221 (1961) (in Japanese)

5 Matsuoka, Y., Sakuma, M., Uruno, T. and Kubota, K.: Characteristics of analgesia induced by noncatecholic phenylethylamine derivatives: Possible involvement of endogenous opioid peptides and serotonin in phenylethylamine analog-induced analgesia. Japan. J. Pharmacol. 34, 277-287 (1984)

6 Braestrup, C. and Randrup, A.: Stereotyped behavior in rats induced by phenylethylamine. dependence on dopamine and noradrenalin, and possible relation to psychoses? In Noncatecholic Phenylethylamines, Part 1. Edited by Mosnaim. A.D. and Wolf. M.T., p. 245-269, Marcel Dekker, New York and Basel (1978)

7 Kuraishi, Y., Harada, Y., Satoh, M. and Takagi, H.: Antagonism by phenoxybenzamine of the analgesic effect of morphine injected into the nucleus reticularis gigantocellularis of the rat. Neuropharmacology. 18, 107-110 (1974)

8 Nakazawa, T., Akaike, A., Satoh, M. and Takagi, T.: Antagonism of stimulation-produced analgesia from the $n$. reticularis paragigantocellularis and $n$. raphe magnus by several blockers in rats. Folia Pharmacol. Japon. 76, 101P (1980) (in Japanese)

9 Paalzow, L.: Analgesia production by clonidine in mice and rats. J. Pharm. Pharmacol. 26, 361363 (1974)

10 Woolfe, G. and MacDonald, A.A.: Evaluation of the analgesic action of pethidine hydrochloride 
(demerol). J. Pharmacol. 80, 300-307 (1944)

11 Ueda, H., Amano, H., Shiomi, H. and Takagi, H.: Comparison of the analgesic effects of various opioid peptides by a newly devised intracisternal injection technique in concious mice. Eur. J. Pharmacol. 56, 265-268 (1979)

12 Karasawa, T., Furukawa, K., Yoshida, K. and Shimizu, M.: A double column procedure for the simultaneous estimation of norepinephrine, normetanephrine, dopamine, 3-methoxytyramine and 5 -hydroxytryptamine in brain tissue. Japan. J. Pharmacol. 25, 727-736 (1975)

13 Ogasawara, S., Mandai, T., Yamatodani, A., Watanabe, T., Wada, H. and Seki, T.: Simple method for the simultaneous determination of noradrenaline, dopamine and serotonin by stepwise elution from a short column of weak cation-exchange resin. J. Chromatogr. 180, 119-126 (1979)

14 Tocco, D.R., Spratto, G.R. and Maickel, R.P.: Differetial analgesic actions of amphetamine enantiomers in the mouse: a drug-drug interaction study. Arch. Int. Pharmacodyn. Ther. 278, 261-272 (1985)

15 Kihara, T. and Kaneto, $H .:$ Important role of adrenergic function in the development of analgesic tolerance to morphine in mice. Japan. J. Pharmacol. 42, 419-423 (1986)
16 Dyck, L.E., Durden, D.A. and Boulton, A.A.: Effects of deuterium substitution on the catabolism of $\beta$-phenylethylamine: an in vivo study. J. Neurochem. 46, 399-404 (1986)

17 Karoum, F., Speciale, S.G., Jr., Chuang, L.-W. and Wyatt, R.J.: Selective effects of phenylethylamine on central catecholamines: A comparative study with amphetamine. J. Pharmacol. Exp. Ther. 223, 432-439 (1982)

18 Koyuncuoglu, H., Eroglu, L. and Güngör, M.: The effects of DL-p-chlorophenylalanine and $D L-\alpha$-methyl-p-tyrosine on the brain catecholamine, serotonin and free amino acid contents in rat. Psychopharmacologia (Berlin) 45, 163166 (1975)

19 Benedetti, M.S. and Dostert, P.: Stereochemical aspects of MAO interactions: reversible and selective inhibitors of monoamine oxidase. Trends Pharmacol. Sci. 6, 246-251 (1985)

20 Guldberg, H.C. and Marsden, C.A.: Catechol-Omethyl transferase: Pharmacological aspects and physiological role. Pharmacol. Rev. 27, 135206 (1975)

21 Kaplan, G.P., Hartman, B.K. and Creveling, C.R.: Immunohistochemical demonstration of catechol-O-methyltransferase in mammalian brain. Brain Res. 167, 241-250 (1979) 